\title{
Michael Schenk
}

\section{Medienwirkungsforschung}

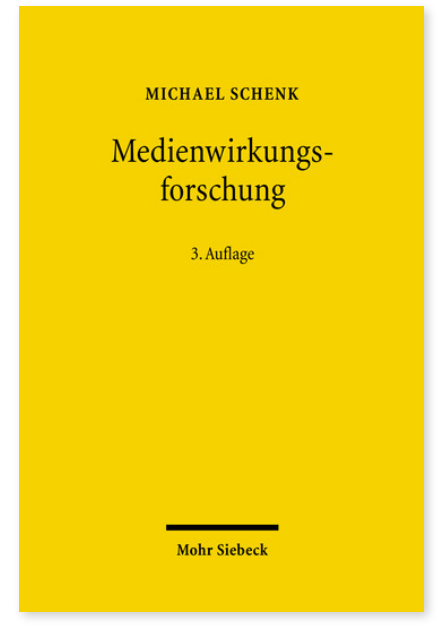

3., vollständig überarbeitete Auflage; 2007. XXIV, 847 Seiten.

ISBN 978-3-16-151656-6

DOI 10.1628/978-3-16-151656-6

eBook PDF $94,00 €$

ISBN 978-3-16-149240-2

fadengeheftete Broschur 94,00€
Dieses inzwischen klassische Werk über die Ansätze und Ergebnisse der Medienwirkungsforschung wurde in der dritten Auflage durchgängig aktualisiert, ergänzt und erweitert. Der zunehmenden Bedeutung von Priming und Framing wurde durch separate Kapitel Rechnung getragen. Das Kapitel zu den Effekten von Gewaltdarstellungen wurde komplett neu bearbeitet. Die Neuauflage gibt nun wieder zuverlässig den aktuellen Stand der Erkenntnisse der Medienwirkungsforschung wieder. "Wie schon in der ersten Auflage besticht Schenks Buch dadurch, dass es alle relevanten Ansätze gelungen präsentiert und bis in theoretische und empirische Details kritisch verfolgt. Zudem wurde die Zweitauflage passagenweise rekonstruiert und um aktuelle theoretische oder empirische Entwicklungen (z.B. wesentliche Arbeiten zum Konstruktivismus) ergänzt. Die resultierende deutliche Volumensteigerung wird durch neue einleitende und resümierende Übersichtsdarstellungen teilkompensiert. Zwar ist Schenks Buch trotzdem nur bedingt für schnelle Leser geeignet - aber aufgrund der profunden Darstellung wieder bzw. immer noch das Standardwerk zur Medienwirkungsforschung.«

Mike Steffen Schäfer in MERZ, Medien und Erziehung 1/48 (2004) S.87f.

»Die dargestellten Themen zur Erforschung der Medienwirkung und der öffentlichen Meinung bieten zahlreiche Anknüpfungspunkte zu politisch relevanten Fragen, so zum Beispiel zu der Agenda-Setting Funktion der Massenmedien. [...] 1987 erstmals erschienen, wurde das Buch für diese zweite Auflage vollständig überarbeitet und durch neue Forschungsergebnisse ergänzt; hinzugekommen ist ein Kapitel zur Informationsverarbeitung.«

Zeitschrift für Politikwissenschaft 2003, S. 221f

Michael Schenk Geboren 1948; Studium der Betriebswirtschaftslehre; 1977 Promotion; 1983 Habilitation; $1984-86$ Professor für Medienwirtschaft und Medienwirkungen an der Johannes-Gutenberg-Universität Mainz; seit 1986 o. Professor für Kommunikationswissenschaft und Sozialforschung an der Universität Hohenheim; seit 1992 geschäftsführender Leiter der Forschungsstelle für Medienwirtschaft und Kommunikationsforschung.

Jetzt bestellen:

https://mohrsiebeck.com/buch/medienwirkungsforschung-9783161516566?no_cache=1

order@mohrsiebeck.com

Telefon: +49 (0)7071-923-17

Telefax: +49 (0)7071-51104 